OPEN ACCESS

Edited by:

Marco Sarà,

San Raffaele Cassino, Italy

Reviewed by:

Sergio Bagnato,

Fondazione Istituto G. Giglio di

Cefalù, Italy

Raffaele Palmirotta,

Università degli studi di

Bari Aldo Moro, Italy

*Correspondence:

Gianluca Castelnuovo

gianluca.castelnuovo@unicatt.it

Specialty section: This article was submitted

to Neurotrauma,

a section of the journal

Frontiers in Neurology

Received: 15 January 2018 Accepted: 19 April 2018

Published: 18 May 2018

Citation:

Castelnuovo G, Giusti EM, Manzoni GM, Saviola D, Gabrielli S,

Lacerenza M, Pietrabissa G,

Cattivelli R, Spatola CAM, Rossi A, Varallo $G$, Novelli $M$, Villa V, Luzzati F,

Cottini A, Lai C, Volpato E,

Cavalera C, Pagnini F, Tesio V,

Castelli L, Tavola M, Torta R,

Arreghini M, Zanini L, Brunani A,

Seitanidis I, Ventura G, Capodaglio P, D'Aniello GE, Scarpina F, Brioschi A, Bigoni M, Priano L, Mauro A, Riva G,

Di Lernia D, Repetto C, Regalia C,

Molinari E, Notaro P, Paolucci S,

Sandrini G, Simpson S,

Wiederhold BK, Gaudio S,

Jackson JB, Tamburin $S$ and

Benedetti F (2018) What Is the Role of the Placebo Effect for Pain Relief in

Neurorehabilitation? Clinical

Implications From the Italian

Consensus Conference on Pain

in Neurorehabilitation.

Front. Neurol. 9:310.

doi: 10.3389/fneur.2018.00310

\section{What Is the Role of the Placebo Effect for Pain Relief in Neurorehabilitation? Clinical Implications From the Italian Consensus Conference on Pain in Neurorehabilitation}

Gianluca Castelnuovo ${ }^{1,2 *}$, Emanuele Maria Giusti ${ }^{1,2}$, Gian Mauro Manzoni ${ }^{1,3}$, Donatella Saviola ${ }^{4}$, Samantha Gabrielli ${ }^{5}$, Marco Lacerenza ${ }^{5}$, Giada Pietrabissa ${ }^{1,2}$, Roberto Cattivelli ${ }^{1,2}$, Chiara Anna Maria Spatola ${ }^{1,2}$, Alessandro Rossi ${ }^{1}$, Giorgia Varallo', Margherita Novelli ${ }^{1}$, Valentina Villa ${ }^{1}$, Francesca Luzzati ${ }^{6}$, Andrea Cottini ${ }^{6}$, Carlo Lai ${ }^{7}$, Eleonora Volpato ${ }^{2,8}$, Cesare Cavalera ${ }^{2}$, Francesco Pagnini ${ }^{2,9}$, Valentina Tesio ${ }^{10}$, Lorys Castelli ${ }^{10}$, Mario Tavola ${ }^{11}$, Riccardo Torta ${ }^{12}$, Marco Arreghini ${ }^{13}$, Loredana Zanini ${ }^{13}$, Amelia Brunani ${ }^{13}$, Ionathan Seitanidis ${ }^{13}$, Giuseppe Ventura ${ }^{13}$, Paolo Capodaglio' ${ }^{13}$, Guido Edoardo D'Aniello ${ }^{1,2}$, Federica Scarpina', Andrea Brioschi ${ }^{14}$, Matteo Bigoni ${ }^{14}$, Lorenzo Priano ${ }^{12,14}$, Alessandro Mauro ${ }^{12,14}$, Giuseppe Riva ${ }^{1,2}$, Daniele Di Lernia ${ }^{2}$, Claudia Repetto ${ }^{2}$, Camillo Regalia'2, Enrico Molinari ${ }^{1,2}$, Paolo Notaro ${ }^{15}$, Stefano Paolucci ${ }^{16}$, Giorgio Sandrini ${ }^{17,18}$, Susan Simpson ${ }^{19,20}$, Brenda Kay Wiederhold ${ }^{21}$, Santino Gaudio ${ }^{22}$, Jeffrey B. Jackson ${ }^{23}$, Stefano Tamburin ${ }^{24}$ and Fabrizio Benedetti ${ }^{2}$ On Behalf of the Italian Consensus Conference on Pain in Neurorehabilitation

${ }^{1}$ Istituto Auxologico Italiano IRCCS, Psychology Research Laboratory, San Giuseppe Hospital, Verbania, Italy, ${ }^{2}$ Department of Psychology, Catholic University of Milan, Milan, Italy, ${ }^{3}$ Faculty of Psychology, eCampus University, Novedrate, Italy, ${ }^{4}$ Cardinal Ferrari Rehabilitation Center, Santo Stefano Rehabilitation Istitute, Fontanellato, Italy, ${ }^{5}$ Pain Medicine Center, San Pio X Clinic, Humanitas, Milan, Italy, ${ }^{6}$ RCCCS Galeazzi Orthopedic Institute, Milan, Italy, ${ }^{7}$ Department of Dynamic and Clinical Psychology, Sapienza University of Rome, Rome, Italy, ${ }^{8} \mathrm{HD}$ Respiratory Rehabilitation Unit, IRCCS Fondazione Don Carlo Gnocchi, Milan, Italy, ${ }^{9}$ Department of Psychology, Harvard University, Cambridge, MA, United States, ${ }^{10}$ Department of Psychology, University of Turin, Turin, Italy, " ${ }^{11}$ Anesthesia and Intensive Care, ASST Lecco, Lecco, Italy, ${ }^{12}$ Department of Neuroscience "Rita Levi Montalcini", University of Turin, Turin, Italy, ${ }^{13}$ Istituto Auxologico Italiano IRCCS, Rehabilitation Unit, San Giuseppe Hospital, Verbania, Italy, ${ }^{14}$ Istituto Auxologico Italiano IRCCS, Department of Neurology and Neurorehabilitation, San Giuseppe Hospital, Verbania, Italy, ${ }^{15}$ Pain Medicine, Anesthesiology Department, A.O. Ospedale Niguarda ca Granda, Milan, Italy, ${ }^{16}$ Fondazione Santa Lucia IRCCS, Rome, Italy, ${ }^{17} \mathrm{C}$. Mondino National Neurological Institute, Pavia, Italy, ${ }^{18}$ Department of Brain and Behavioral Sciences, University of Pavia, Pavia, Italy, ${ }^{19}$ University of South Australia, Adelaide, SA, Australia, ${ }^{20}$ Regional Eating Disorders Unit, NHS Lothian, Livingston, United Kingdom, ${ }^{21}$ Virtual Reality Medical Institute, Brussels, Belgium, ${ }^{22}$ Department of Neuroscience, Functional Pharmacology, Uppsala University, Uppsala, Sweden, ${ }^{23}$ Virginia Tech, Falls Church, VA, United States, ${ }^{24}$ Department of Neurosciences, Biomedicine and Movement Sciences, University of Verona, Verona, Italy

Background: It is increasingly acknowledged that the outcomes of medical treatments are influenced by the context of the clinical encounter through the mechanisms of the placebo effect. The phenomenon of placebo analgesia might be exploited to maximize the efficacy of neurorehabilitation treatments. Since its intensity varies across neurological disorders, the Italian Consensus Conference on Pain in Neurorehabilitation (ICCP) summarized the studies on this field to provide guidance on its use. 
Methods: A review of the existing reviews and meta-analyses was performed to assess the magnitude of the placebo effect in disorders that may undergo neurorehabilitation treatment. The search was performed on Pubmed using placebo, pain, and the names of neurological disorders as keywords. Methodological quality was assessed using a pre-existing checklist. Data about the magnitude of the placebo effect were extracted from the included reviews and were commented in a narrative form.

Results: 11 articles were included in this review. Placebo treatments showed weak effects in central neuropathic pain (pain reduction from 0.44 to 0.66 on a $0-10$ scale) and moderate effects in postherpetic neuralgia (1.16), in diabetic peripheral neuropathy (1.45), and in pain associated to HIV (1.82). Moderate effects were also found on pain due to fibromyalgia and migraine; only weak short-term effects were found in complex regional pain syndrome. Confounding variables might have influenced these results.

Clinical implications: These estimates should be interpreted with caution, but underscore that the placebo effect can be exploited in neurorehabilitation programs. It is not necessary to conceal its use from the patient. Knowledge of placebo mechanisms can be used to shape the doctor-patient relationship, to reduce the use of analgesic drugs and to train the patient to become an active agent of the therapy.

Keywords: neurorehabilitation, placebo, pain, clinical psychology, health psychology, placebo effect, consensus conference

\section{INTRODUCTION}

The placebo effect can be defined as the improvement in the patient's symptoms after the administration of an inert substance in a context inducing positive expectations about its effects $(1,2)$. This phenomenon is raising a growing interest in the field of pain management in patients with neurological disorders. Neurorehabilitation treatments could be delayed or hampered by pain symptoms, whose management could be particularly difficult since the available treatments may provide only a moderate relief at the cost of various undesirable side effects (3-5). In this context, knowledge of the mechanisms of the placebo effect could be important. Rather than representing an alternative treatment modality, this phenomenon can be exploited to enhance the effectiveness of the care (6).

In the last decades, research has shifted its focus from the inert substance to the psychosocial context surrounding its administration. The placebo response can be considered as a form of contextual healing, since the beneficial outcome is due to the context of the clinical encounter, rather than to a specific efficacy of the actual treatment (7-9). This complex phenomenon can be described as the emerging effect of the doctor-patient relationship and of the psychosocial context in which it takes place (10). The patient's memory of previous treatments, personal characteristics, and expectations modulate and are modulated by the interaction with the doctor, whose characteristics and expectations, in turn, influence the context of the encounter. Therefore, the therapeutic ritual itself is the trigger of the placebo effect (11).

The placebo effect is grounded in physiological mechanisms. Different processes can be involved, depending both on the physical or psychological state of the patient and on the context. Various theoretical frameworks have been proposed to understand them, each focusing on a different set of variables, such as conditioning processes, patient expectations, individual attributions, and contextual factors $(2,12)$. Each of these processes was found to involve different neurobiological mechanisms, including opioid, endocannabinoid, or dopamine ones (13-20). The presence of various mechanisms seems to reflect the complexity of the phenomenon, as well as the variety of neurobiological, psychological, and psychosocial processes involved.

The placebo effect varies across individuals and disorders. Studies are increasingly shedding some light on the individual differences, focusing on the role of genetics (21-23), on differences in the activation of the reward system (16), on differences in expectancy mechanisms and in the emotional appraisal of situations (24), or on the role of psychological variables. Among them, preliminary data corroborate the role of dispositional optimism and state anxiety (25-27), various personality traits $(28,29)$, hypnotizability and suggestibility $(30,31)$, reappraisal ability (32), beliefs (33), learning mechanisms (34), and traits linked to dopaminergic mechanisms such as novelty seeking (35).

On the other hand, differences across disorders have received less attention, especially in the field of neurorehabilitation. To exploit the analgesic potential of placebo treatments in this field, knowledge about its differential effects is required. On behalf of The Italian Consensus Conference on Pain in Neurorehabilitation (ICCPN), a multidisciplinary board aimed at developing the national guidelines on the assessment and treatment of pain in neurorehabilitation, our working group was established to summarize the available studies on this topic.

\section{METHODS}

A review of the existing reviews and meta-analyses examining the role of the placebo effect in disorders that may undergo 
neurorehabilitation treatment was performed. This research design was chosen since (a) it allowed to summarize a high amount of studies on such a broad topic and (b) literature reviews focusing on each disorder were already present. Both systematic and non-systematic reviews were considered for inclusion since it was hypothesized that the quality of the existing literature about each disorder would be heterogeneous. Studies were, therefore, included if they reported reviews, with or without meta-analysis, presenting data about the effects of a placebo treatment on pain intensity in disorders that may undergo neurorehabilitation treatment. Only articles written in English language were considered. Studies were excluded if they did not report summary data about the effects of placebo treatments.

An initial search was performed on July 2014, imposing no restraints on the articles' publication date. Subsequently, a research update took place on March 2017, restraining the search to articles published from 2014 to 2017. Both the searches were performed on PubMed using the following keywords: "placebo" (research restricted to the title) "nervous system disease" (as a $\mathrm{MeSH}$ word), the names of the primary neurological disorders and "pain." The inclusion and exclusion criteria were used by one of the authors to judge the eligibility of the studies based on the articles' titles, abstracts and, finally, full texts. The bibliographies of the selected articles were analyzed to identify other potentially relevant reviews. The methodological quality of included studies was then assessed using the Critical Appraisal Checklist for Systematic Reviews (Table 1) (36). When assessing the methodological quality of non-systematic reviews, items from 5 to 8 of this checklist were not considered.

The following data were extracted from the included reviews: study design of the review, disorder addressed by the review, participants' details, study design of the included studies, number of electronic databases accessed during the search, date range of the search, number of studies included, number of subjects included in placebo arms, total number of subjects, instruments used by the studies to assess pain intensity, and quantitative results. Since the aim of the present review was not to assess if placebo treatments are evidence-based interventions, the quality of evidence was not graded and no recommendations were made. Instead, the results of the reviews were synthesized in a narrative form. Results from excluded reviews or from primary studies that were found during the search that were considered relevant to give insight to areas not explored by the included reviews were also commented.

TABLE 1 | Critical Appraisal Checklist for Systematic Reviews.

1 Is the review question clearly and explicitly stated?

2 Were the inclusion criteria appropriate for the review question?

3 Was the search strategy appropriate?

4 Were the sources and resources used to search for studies adequate?

5 Were the criteria for appraising studies appropriate?

6 Was critical appraisal conducted by two or more reviewers independently?

7 Were the methods used to combine studies appropriate?

8 Was the likelihood of publication bias assessed?

9 Were recommendations for policy and/or practice supported by the reported data?

10 Were the specific directives for new research appropriate?

\section{RESULTS}

Overall, the searches yielded 872 records. From this sample, 11 reviews were included in the present review. The flowchart of the study search and selection is reported in Figure 1.

Among the included reviews, 10 out of 11 were systematic and 9 included a meta-analysis. Five of these reviews focused on peripheral and/or central neuropathic pain disorders, three on migraine and the remaining on chronic regional pain syndrome, fibromyalgia, or mixed chronic pain conditions. The characteristics of the studies are reported in Table 2 .

The methodological quality of the included reviews was variable (Table 3). Among the systematic reviews, three studies did not meet at least six items of the critical appraisal checklist $(39,40,44)$, but none of them showed substantial biases that may hinder the interpretation of their results.

\section{PLACEBO EFFECT IN PAIN CONDITIONS IN NEUROREHABILITATION}

The main quantitative results of the included reviews generally show that the placebo effect has a low to moderate effect on pain across the various disorders (Table 4). However, differences are visible, especially when neuropathic and non-neuropathic pain disorders are contrasted.

Various reviews and meta-analyses addressed the role of placebo in neuropathic pain disorders and found a noticeable heterogeneity between peripheral and central ones (43-46). In general, the placebo effect was found to be more intense in the former than in the latter. A meta-analytic study estimated the intensity of the placebo effect in various neuropathic pain disorders, and explored both the average pain reduction and the percentage of patients who positively responded to the placebo treatment (44). On a $0-10$ scale, the average decrease in pain severity was 1.82 in pain associated with HIV (percentage of positive responders: $48.2 \%$ ), 1.45 in painful diabetic peripheral neuropathy (percentage of positive responders: $20 \%$ ), 1.16 in postherpetic neuralgia (percentage of positive responders: $11.5 \%$ ), and between 0.44 and 0.64 in central neuropathic pain (percentage of positive responders: $7.2 \%)(42,44)$. Other studies confirmed that, among the disorders associated with peripheral neuropathic pain, the placebo effect was higher in painful diabetic peripheral neuropathy than in postherpetic neuralgia (43). In contrast, the placebo effect in complex regional pain syndrome, a disorder with some neuropathic characteristics (48), seems to be nearly absent, with only weak short-term effects (37). In neuropathic pain disorders, the intensity of the placebo effect is modulated by the duration of treatment, with longer treatments associated with increased effects, and by the duration and intensity of initial pain, with longer duration of and higher intensity associated with a reduced placebo response $(42,43,45)$.

The intensity of the placebo effect is generally higher in nonneuropathic pain disorders. A meta-analysis by Madsen et al. (47) compared the effects of acupuncture, placebo acupuncture, and a no-treatment condition on pain from various disorders, including headache (tension type, migraine), nociceptive pain (osteoarthritis, low back pain), iatrogenic pain (postoperative, 

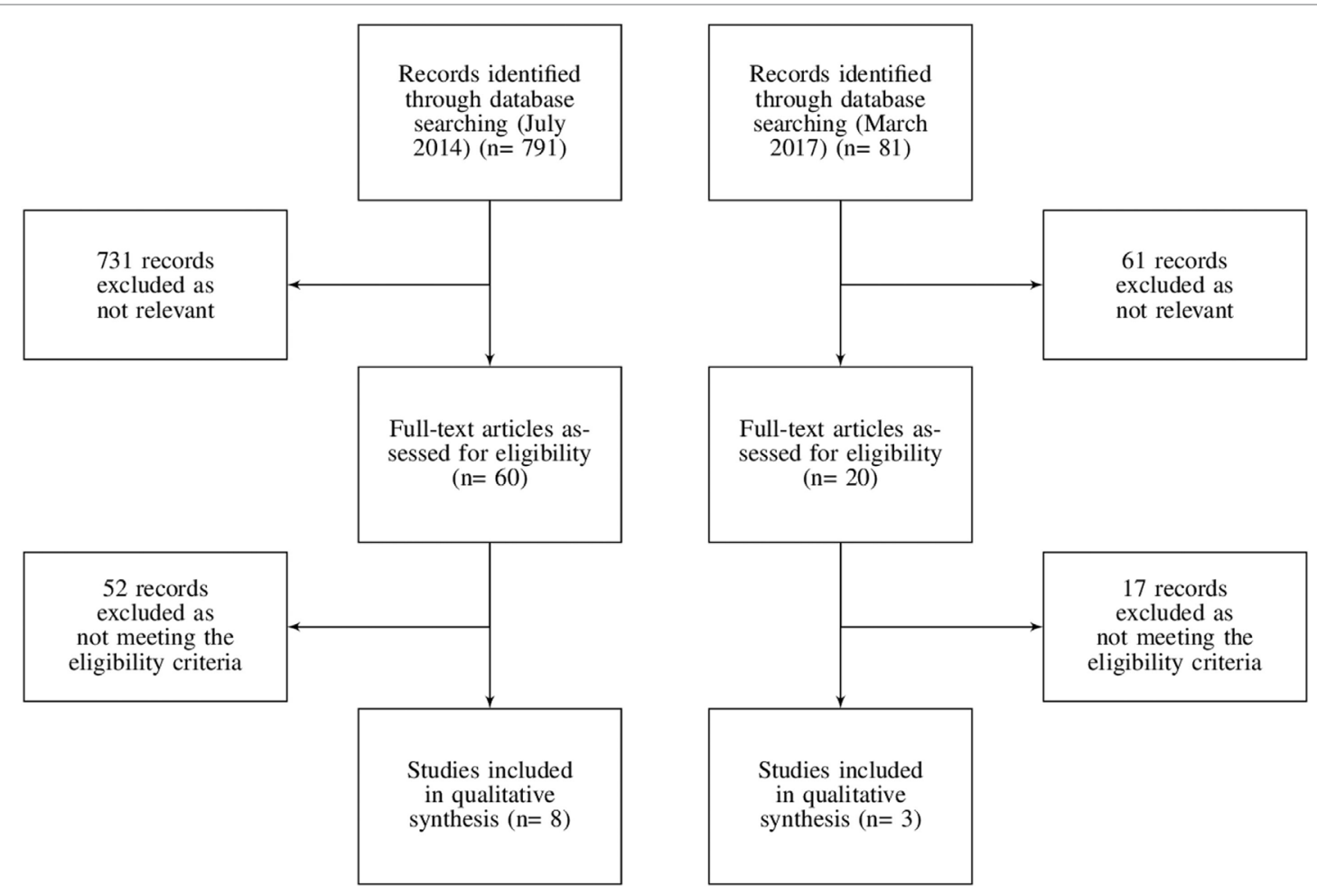

FIGURE 1 | Flowchart of the records search and selection.

procedural pain during colonoscopy, abdominal scar pain), and fibromyalgia. In this study, acupuncture was found to have slightly stronger effects (i.e., 0.4 points on a $0-10$ scale) than placebo acupuncture, whereas a moderate difference (i.e., 1.0 points) was found between placebo acupuncture and no acupuncture conditions.

Hauser et al. (38) studied both the placebo and the nocebo effect in the management of fibromyalgia, and estimated that the percentage of patients experiencing a $50 \%$ pain reduction after a placebo treatment was $18.6 \%$ and that the dropout rate due to adverse events was $10.9 \%$. In contrast, groups receiving a true drug showed a higher rate of responders (31.6\%) and a higher dropout rate due to adverse events (20.4\%). This study did not compare the improvement in the placebo group with that in the untreated groups.

Despite the variability of their effects, placebo treatments were found to be associated with both short- and long-term improvements in migraine sufferers $(39,41)$. Placebo groups showed an improvement of pain symptoms in $26 \%$ of cases, and $21 \%$ of patients taking placebo for migraine prophylaxis improved. For both outcomes, the efficacy of the placebo treatment was estimated to be half of that of active drugs. The placebo treatment type influenced its efficacy, with sham acupuncture and sham surgery being more effective than oral placebos (41). These effects were accompanied by a high rate of adverse events (39-41). The presence of adverse events in case of placebo administration is in line with the nature of placebo, since their characteristics are generally similar to the characteristics of the active drugs against which placebo is compared (49).

The size of the placebo effect and its variability across disorders and type of placebo treatment is apparent also when non-neurological disorders are considered. It was estimated that placebo treatments for osteoarthritis resulted in an overall moderate effect (effect size $=0.51$ ) and that topical and intraarticular placebos are more effective than oral ones (effect size differences of 0.20 and 0.29 , respectively) $(50,51)$. Other estimates show that the size of the placebo effect is equivalent to $72 \%$ of that of the drug treatment in burning mouth syndrome (52) and that it leads to pain remission rates of $19.9 \%$ in chronic pancreatitis (53).

\section{IMPLICATIONS FOR CLINICAL PRACTICE}

The effectiveness of placebo treatments should not be overestimated. Most of the studies on this topic showed high heterogeneity and did not take into account confounding variables, such as spontaneous remission of symptoms or regression toward the mean, thus potentially overestimating the intensity of the placebo response. In addition, various authors underlined that (a) placebo effect is higher when subjective rather than objective outcome measures are explored (54); (b) bias may be present in patients' responses (54); (c) each individual responds differently to placebos $(55,56)$, and (d) outcomes vary consistently across studies and methodological design (57). These limitations are prominent in studies on placebo treatments, and may impede 
TABLE 2 | Description of the included reviews.

\begin{tabular}{|c|c|c|c|c|c|c|c|c|c|}
\hline Reference & Type of review & Disorder & Participants details & $\begin{array}{l}\text { Study design of the } \\
\text { included studies }\end{array}$ & $\begin{array}{c}\text { Number of } \\
\text { databases } \\
\text { searched }\end{array}$ & $\begin{array}{l}\text { Date range of } \\
\text { the database } \\
\text { search }\end{array}$ & $\begin{array}{l}\text { Number of } \\
\text { trials included }\end{array}$ & $\begin{array}{l}\text { Number of } \\
\text { subjects in } \\
\text { placebo arms }\end{array}$ & $\begin{array}{l}\text { Total } \\
\text { number of } \\
\text { subjects }\end{array}$ \\
\hline Mbizvo et al. (37) & Meta-analysis & $\begin{array}{l}\text { Complex } \\
\text { regional pain } \\
\text { Syndrome }\end{array}$ & $\begin{array}{l}\text { Patients with complex regional pain } \\
\text { syndrome I and II }\end{array}$ & $\begin{array}{l}\text { RCT and controlled } \\
\text { studies }\end{array}$ & $\begin{array}{l}5 \text { (+ other } \\
\text { sources) }\end{array}$ & 1966-2013 & $\begin{array}{c}20 \text { ( } 18 \\
\text { included in the } \\
\text { meta-analysis) }\end{array}$ & 340 & Not reported \\
\hline Hauser et al. (38) & Meta-analysis & Fibromyalgia & $\begin{array}{l}\text { Patients with fibromyalgia, both males and } \\
\text { females }\end{array}$ & Double-blind RCT & 3 & up to 2012 & 18 & 3,546 & 6,589 \\
\hline Loder et al. (39) & Meta-analysis & Migraine & Acute migraine sufferers & $\mathrm{RCT}$ and controlled trials & 1 & 1991-2002 & 31 & Not reported & Not reported \\
\hline Macedo et al. (40) & Meta-analysis & Migraine & Migraine sufferers & Double-blind RCT & 1 & 1998-2004 & $\begin{array}{l}32(22 \\
\text { included in the } \\
\text { meta-analysis) }\end{array}$ & 1,416 & 4,519 \\
\hline Meissner et al. (41) & Meta-analysis & Migraine & Migraine sufferers & $\mathrm{RCT}$ & 4 & up to 2012 & $\begin{array}{l}102 \text { ( } 79 \\
\text { included in the } \\
\text { meta-analysis) }\end{array}$ & Not reported & 9,287 \\
\hline Cragg et al. (42) & Meta-analysis & $\begin{array}{l}\text { Neuropathic } \\
\text { pain (central) }\end{array}$ & $\begin{array}{l}\text { Patients with spinal cord injury, stroke or } \\
\text { multiple sclerosis }\end{array}$ & Placebo-controlled trials & 1 & up to 2015 & 39 & 1,153 & Not reported \\
\hline Arakawa et al. (43) & Meta-analysis & $\begin{array}{l}\text { Neuropathic } \\
\text { pain }\end{array}$ & $\begin{array}{l}\text { Patients with peripheral or central } \\
\text { neuropathic pain }\end{array}$ & Placebo-controlled trials & 3 & 1995-2014 & 71 & Not reported & 6,126 \\
\hline Cepeda et al. (44) & Meta-analysis & $\begin{array}{l}\text { Neuropathic } \\
\text { pain }\end{array}$ & $\begin{array}{l}\text { Diabetic neuropathy, postherpetic neuralgia, } \\
\text { central neuropathic pain, HIV-associated } \\
\text { neuropathic pain }\end{array}$ & RCT & $\begin{array}{l}1 \text { (+ other } \\
\text { sources) }\end{array}$ & 1995-2009 & 141 & Not reported & 6,239 \\
\hline $\begin{array}{l}\text { Quessy and } \\
\text { Rowbotham (45) }\end{array}$ & Topical review & $\begin{array}{l}\text { Neuropathic } \\
\text { pain }\end{array}$ & $\begin{array}{l}\text { Patients with painful diabetic neuropathy or } \\
\text { postherpetic neuralgia }\end{array}$ & RCT & Not reported & Not reported & 35 & 3,355 & Not reported \\
\hline Tuttle et al. (46) & $\begin{array}{l}\text { Systematic } \\
\text { review }\end{array}$ & $\begin{array}{l}\text { Neuropathic } \\
\text { pain }\end{array}$ & $\begin{array}{l}\text { Patients with various types of neuropathic } \\
\text { pain }\end{array}$ & Double-blind RCT & 3 & 1980-2013 & 84 & Not reported & Not reported \\
\hline Madsen et al. (47) & Meta-analysis & Chronic pain & $\begin{array}{l}\text { Patients with headache, migraine, } \\
\text { osteoarthritis, low back pain, postoperative } \\
\text { pain, colonoscopy, fibromyalgia or scar pain }\end{array}$ & 3-armed RCT & 5 & up to 2008 & 13 & 943 & 3,025 \\
\hline
\end{tabular}

$R C T$, randomized controlled trials. 
TABLE 3 | Quality assessment of the included reviews.

\begin{tabular}{|c|c|c|c|c|c|c|c|c|c|c|}
\hline Reference & Item 1 & Item2 & Item 3 & Item 4 & Item 5 & Item 6 & Item 7 & Item 8 & Item 9 & Item 10 \\
\hline Mbizvo et al. (37) & $\checkmark$ & $\checkmark$ & $\checkmark$ & $\checkmark$ & $\checkmark$ & $\checkmark$ & $\checkmark$ & $\checkmark$ & $\checkmark$ & $\checkmark$ \\
\hline Hauser et al. (38) & $\checkmark$ & $\checkmark$ & $\checkmark$ & $\checkmark$ & $x$ & $x$ & $\checkmark$ & $x$ & $\checkmark$ & $\checkmark$ \\
\hline Loder et al. (39) & $\checkmark$ & $x$ & $x$ & $x$ & $\checkmark$ & $x$ & $\checkmark$ & $x$ & $\checkmark$ & $x$ \\
\hline Macedo et al. (40) & $\checkmark$ & $\checkmark$ & $\checkmark$ & $\times$ & $\times$ & $\times$ & $\checkmark$ & $x$ & $\times$ & $x$ \\
\hline Meissner et al. (41) & $\checkmark$ & $\checkmark$ & $\checkmark$ & $\checkmark$ & $\checkmark$ & $\checkmark$ & $\checkmark$ & $x$ & $\checkmark$ & $\checkmark$ \\
\hline Cragg et al. (42) & $\checkmark$ & $\checkmark$ & $\checkmark$ & $x$ & $x$ & $x$ & $\checkmark$ & $\checkmark$ & $\checkmark$ & $\checkmark$ \\
\hline Arakawa et al. (43) & $\checkmark$ & $\checkmark$ & $\checkmark$ & $\checkmark$ & $x$ & $x$ & $\checkmark$ & $x$ & $\checkmark$ & $\checkmark$ \\
\hline Cepeda et al. (44) & $\checkmark$ & $\checkmark$ & $\checkmark$ & $\times$ & $\times$ & $\times$ & $\checkmark$ & $x$ & $\checkmark$ & $x$ \\
\hline Quessy and Rowbotham (45) & $x$ & $\checkmark$ & $x$ & $\times$ & nla & nla & nla & n\a & $\checkmark$ & $x$ \\
\hline Tuttle et al. (46) & $\checkmark$ & $\checkmark$ & $\checkmark$ & $\checkmark$ & $\times$ & $\times$ & $\checkmark$ & $\checkmark$ & $\checkmark$ & $\checkmark$ \\
\hline Madsen et al. (47) & $\checkmark$ & $\checkmark$ & $\checkmark$ & $\checkmark$ & $\checkmark$ & $\checkmark$ & $\checkmark$ & $x$ & $\checkmark$ & $\checkmark$ \\
\hline
\end{tabular}

TABLE 4 | Quantitative findings of the included reviews.

\begin{tabular}{|c|c|c|c|c|}
\hline Reference & Disorder & $\begin{array}{l}\text { Instruments or outcome } \\
\text { data }\end{array}$ & Results & Comments \\
\hline \multirow[t]{4}{*}{$\begin{array}{l}\text { Mbizvo } \\
\text { et al. (37) }\end{array}$} & \multirow{4}{*}{$\begin{array}{l}\text { Complex } \\
\text { Regional Pain } \\
\text { Syndrome }\end{array}$} & \multirow[t]{4}{*}{$\begin{array}{l}\text { VAS, NRS (if other scales were } \\
\text { used, scores were converted) }\end{array}$} & $\begin{array}{l}\text { Mean change in } 0-100 \text { VAS or NRS at } 15-30 \mathrm{~min} \\
\text { posttreatment: } 18,423,95 \% \mathrm{Cl}[-33.15,-3.65]\end{array}$ & \multirow{4}{*}{$\begin{array}{l}\text { Only mean change at } 15-30 \text { min } \\
\text { posttreatment was significant. Study } \\
\text { design and invasiveness of the placebo } \\
\text { treatment affected placebo response }\end{array}$} \\
\hline & & & $\begin{array}{l}\text { Mean change in } 0-100 \text { VAS or NRS at } 1 \text { week } \\
\text { posttreatment: }-6,772,95 \% \mathrm{Cl}[-14.92,1.38]\end{array}$ & \\
\hline & & & $\begin{array}{l}\text { Mean change in } 0-100 \text { VAS or NRS at } 3-4 \text { weeks } \\
\text { posttreatment: } 0.326,95 \% \mathrm{Cl}[-2.329,2.981]\end{array}$ & \\
\hline & & & $\begin{array}{l}\text { Mean change in } 0-100 \text { VAS or NRS at } 6 \text { weeks } \\
\text { posttreatment: }-3.87,95 \% \mathrm{Cl}[-9.48,1.71]\end{array}$ & \\
\hline
\end{tabular}

\begin{tabular}{|c|c|c|c|}
\hline $\begin{array}{l}\text { Hauser } \\
\text { et al. (38) }\end{array}$ & Fibromyalgia & $0-10$ or $0-100$ VAS or NRS & $\begin{array}{l}\text { Percentage of patients with a } 50 \% \text { reduction of pain } \\
\text { intensity in placebo arms: } 18.6 \%, 95 \% \mathrm{Cl}[17.4-19.9] \text { vs } \\
31.6 \%, 95 \% \mathrm{Cl}[30.5,32.7] \text { of patients in active drugs }\end{array}$ \\
\hline
\end{tabular}
arms

Nocebo effect: dropout due to adverse events: 10.9\%, 95\% Cl [9.9-11.9]. Confounders: percentage of women or Caucasians included and study duration are positively correlated with placebo effect, number of continents is negatively associated with placebo effect

\begin{tabular}{|c|c|c|c|c|}
\hline \multirow[t]{3}{*}{$\begin{array}{l}\text { Loder } \\
\text { et al. (39) }\end{array}$} & \multirow[t]{3}{*}{ Migraine } & \multirow{3}{*}{$\begin{array}{l}\text { Percentage of pain-free } \\
\text { patients, response rate, } \\
\text { adverse events rate }\end{array}$} & $\begin{array}{l}\text { Percentage of pain-free patients at two hours: } 6.08 \% \\
( \pm 4.83)\end{array}$ & \multirow{3}{*}{$\begin{array}{l}\text { Migraine prophylaxis: percentage of } \\
\text { pain-free patients: } 6.02 \% \text {; response rate: } \\
25.52 \% \text {; adverse events rate: } 19.56 \%\end{array}$} \\
\hline & & & Response rate at 2 h: $28.90 \%( \pm 8.55)$ & \\
\hline & & & Adverse events rate at $2 \mathrm{h:} 23.4 \%( \pm 14.05)$ & \\
\hline \multirow[t]{3}{*}{$\begin{array}{l}\text { Macedo } \\
\text { et al. (40) }\end{array}$} & \multirow[t]{3}{*}{ Migraine } & \multirow{3}{*}{$\begin{array}{l}\text { Percentage of improved } \\
\text { patients, attacks per month } \\
\text { reduction, adverse events rate }\end{array}$} & $\begin{array}{l}\text { Migraine prophylaxis: percentage of improved patients: } \\
21 \%, 95 \% \mathrm{Cl}[13 \%, 28 \%]\end{array}$ & \multirow[t]{3}{*}{$\begin{array}{l}\text { Significant confounders: study design } \\
\text { and country }\end{array}$} \\
\hline & & & Attacks per month reduction: $-0.8,95 \% \mathrm{Cl}[0.4,1.1]$ & \\
\hline & & & Adverse events rate: $30 \%, 95 \% \mathrm{Cl}[17 \%, 43 \%]$ & \\
\hline \multirow[t]{2}{*}{$\begin{array}{l}\text { Meissner } \\
\text { et al. (41) }\end{array}$} & \multirow[t]{2}{*}{ Migraine } & \multirow{2}{*}{$\begin{array}{l}\text { Proportion of responders } \\
\text { (directly extracted or calculated } \\
\text { from: number of days with } \\
\text { migraine, number of days with } \\
\text { headache, or } 50 \% \text { decrease in }\end{array}$} & $\begin{array}{l}\text { Proportion of placebo responders at } 3-4 \text { months: } 0.26 \text {, } \\
95 \% \mathrm{Cl}[0.22,0.30] \text { vs responders to active treatments: } \\
0.42,95 \% \mathrm{Cl}[0.38,0.45]\end{array}$ & \multirow[t]{2}{*}{$\begin{array}{l}\text { Subgroup analysis: when all confounders } \\
\text { are considered, blinding of subjects and } \\
\text { type of placebo treatment is positively } \\
\text { correlated with placebo magnitude }\end{array}$} \\
\hline & & & Difference between placebo treatments: sham surgery: & \\
\hline
\end{tabular}
headache, or $50 \%$ decrease in $\quad 0.58,95 \% \mathrm{Cl}[0.37,0.77]$; sham acupuncture: $0.38,95 \%$ $\mathrm{Cl}$ [0.30, 0.47]; oral placebo: 0.22, 95\% Cl [0.17, 0.28]

\begin{tabular}{|c|c|c|c|}
\hline $\begin{array}{l}\text { Cragg } \\
\text { et al. (42) }\end{array}$ & $\begin{array}{l}\text { Neuropathic } \\
\text { pain (central) }\end{array}$ & VAS, NRS & $\begin{array}{l}\text { Overall mean change in pain rating }(0-10):-0.6495 \% \mathrm{Cl} \\
{[-0.83,-0.45]}\end{array}$ \\
\hline
\end{tabular}

Meta-regression: weaker placebo effect associated with higher chronic pain duration, baseline pain variability, crossover study design. High heterogeneity

\begin{tabular}{|c|c|}
\hline $\begin{array}{l}\text { Arakawa } \\
\text { et al. (43) }\end{array}$ & $\begin{array}{l}\text { Neuropathic } \\
\text { pain }\end{array}$ \\
\hline
\end{tabular}

Neuropathic pain (both central and peripheral): percentage of patients with 50\% pain intensity reduction: $23 \%$, 95\% Cl [20\%, 25\%], percentage of patients with 30\% pain intensity reduction: 37\%, 95\% Cl [34\%, 41\%]

Among the results of the multivariable analysis, baseline pain intensity was found to be negatively correlated with placebo response in postherpetic

Peripheral neuropathic pain: percentage of patients with $50 \%$ pain intensity reduction: $23 \%, 95 \% \mathrm{Cl}[21,26]$, neuralgia and in painful diabetic peripheral neuropathy percentage of patients with $30 \%$ pain intensity reduction: $39 \%, 95 \%$ Cl [34\%, 42\%] 
TABLE 4 | Continued

\begin{tabular}{|c|c|c|c|c|}
\hline Reference & Disorder & $\begin{array}{l}\text { Instruments or outcome } \\
\text { data }\end{array}$ & Results & Comments \\
\hline & & & $\begin{array}{l}\text { Central neuropathic pain: percentage of patients with } 50 \% \\
\text { pain intensity reduction: } 14 \%, 95 \% \mathrm{Cl}[10,19] \text {, percentage } \\
\text { of patients with } 30 \% \text { pain intensity reduction: } 26 \%, 95 \% \\
\text { Cl }[19 \%, 33 \%]\end{array}$ & \\
\hline \multirow[t]{5}{*}{$\begin{array}{l}\text { Cepeda } \\
\text { et al. (44) }\end{array}$} & \multirow[t]{5}{*}{$\begin{array}{l}\text { Neuropathic } \\
\text { pain }\end{array}$} & \multirow{5}{*}{$\begin{array}{l}\text { Mean decrease in } 0-10 \text { pain } \\
\text { intensity, responder rate } \\
\text { (percentage of patients with } \\
50 \% \text { pain intensity reduction) }\end{array}$} & $\begin{array}{l}\text { Overall: } 1.2( \pm 1.0) \text { mean reduction in pain intensity, RR } \\
17 \% \text { (range: } 0-43 \%)\end{array}$ & \multirow{5}{*}{$\begin{array}{l}\text { Trials evaluating NMDA blockers } \\
\text { showed weaker placebo response, age } \\
\text { was positively correlated with placebo } \\
\text { response }\end{array}$} \\
\hline & & & $\begin{array}{l}\text { Diabetic neuropathy: } 1.45,95 \% \mathrm{Cl}[1.35-1.55] \text { mean } \\
\text { reduction in pain intensity, } \mathrm{RR} \text { of } 20.2 \%, 95 \% \mathrm{Cl} \\
{[14.6-25.8]}\end{array}$ & \\
\hline & & & $\begin{array}{l}\text { Postherpetic neuralgia: } 1.16,95 \% \mathrm{Cl}[1.03-1.29] \text { mean } \\
\text { reduction in pain intensity, RR of } 11.5 \%, 95 \% \mathrm{Cl}[8.4-14.5]\end{array}$ & \\
\hline & & & $\begin{array}{l}\text { Central neuropathic pain } 0.53,95 \% \mathrm{Cl}[0.19-0.86] \text { mean } \\
\text { reduction in pain intensity, } \mathrm{RR} \text { of } 7.2 \%, 95 \% \mathrm{Cl}[2.1-12.3]\end{array}$ & \\
\hline & & & $\begin{array}{l}\text { HIV-associated neuropathic pain: } 1.82,95 \% \mathrm{Cl}[1.51- \\
2.12], \mathrm{RR} \text { of } 42.8 \%, 95 \% \mathrm{Cl}[34.9-50.7]\end{array}$ & \\
\hline $\begin{array}{l}\text { Quessy and } \\
\text { Rowbotham } \\
(45)\end{array}$ & $\begin{array}{l}\text { Neuropathic } \\
\text { pain }\end{array}$ & VAS, NRS & $\begin{array}{l}\text { Median change in pain intensity in PDN: 26\% (range } \\
11-35 \% \text { ); in PHN 15-16 (range 4-44\%) }\end{array}$ & $\begin{array}{l}\text { The placebo response was found to vary } \\
\text { throughout the time course of trials and } \\
\text { to be influenced by trial duration }\end{array}$ \\
\hline $\begin{array}{l}\text { Tuttle } \\
\text { et al. (46) }\end{array}$ & $\begin{array}{l}\text { Neuropathic } \\
\text { pain }\end{array}$ & VAS, NRS & $\begin{array}{l}\text { Mean change in pain intensity: } 18.3 \%, 95 \% \mathrm{Cl} \\
{[15.2 \%, 21.4 \%]}\end{array}$ & $\begin{array}{l}\text { Multivariable analysis: placebo } \\
\text { magnitude is positively correlated with } \\
\text { sample size; in studies performed in the } \\
\text { US the placebo magnitude is positively } \\
\text { correlated with study duration }\end{array}$ \\
\hline $\begin{array}{l}\text { Madsen } \\
\text { et al. (47) }\end{array}$ & $\begin{array}{l}\text { Various types } \\
\text { of pain }\end{array}$ & $\begin{array}{l}\text { SMD based on WOMAC, VAS } \\
\text { or Likert-type rating scales }\end{array}$ & $\begin{array}{l}\text { Acupuncture vs placebo SMD: }-0.17,95 \% \mathrm{Cl}[-0.26 \text {, } \\
-0.08] ; \text { placebo vs nontreated controls SMD: }-0.42 \\
95 \% \mathrm{Cl}[-0.60,-0.23]\end{array}$ & High heterogeneity \\
\hline
\end{tabular}

VAS, Visual Analogue Scale; NRS, Numeric Rating Scale; MPQ, McGill Pain Questionnaire; WOMAC, Western Ontario and McMaster Universities Osteoarthritis Index Pain Score; CI, Confidence Interval; SMD, standardized mean difference; $R R$, responders rate.

to predict their effects in routine clinical practice. It is recommended to take these treatments into consideration in neurorehabilitation settings only after traditional ones have failed or are contraindicated (58-64).

Rather than simply representing an alternative type of treatment, the placebo effect is a phenomenon that can increase the effectiveness of the care, since it constitutes the process through which the doctor-patient relationship becomes therapeutic. The knowledge of relevance of the placebo effect for each specific pain disorder is recommended to exploit its potential. For example, placebo response is generally small in central neuropathic pain, where pharmacological and nonpharmacological treatments have also limited efficacy, while it appears to represent half of the effect of active treatments in the prophylaxis of primary headaches. This information is central to shape the communication with the patient, allowing to provide a trustworthy explanation of the positive effects of the therapeutic context.

It is increasingly acknowledged that concealment is not necessary for the placebo effect to take place. Research on open-label placebos treatments, i.e., non-deceptive treatments in which the participants are alerted that the therapeutic mean is inert, but are informed about the effects of the administration of placebos, corroborates this claim. Further studies are needed, but open-label placebo treatments seem to have a similar or even higher efficacy than deceptive ones and are associated with marked improvement of symptoms of a variety of conditions $(65-70)$. These treatments are more easily accepted by patients (71) and overcome the ethical and legal implications of the deceitful prescription of placebos, which violates the principle of the informed consent and may affect the trust that shape the doctor-patient relationship $(72,73)$.

Various techniques can be used to improve the patient's symptoms through placebo mechanisms. A possible strategy is to maximize the patient's expectations regarding the treatment. This can be done by informing the patient on the nature and effects of placebo analgesia, by assessing the appropriateness of the patient's beliefs about his disorder and its treatment and providing information in case they are excessively positive or negative. In this case, it would be important to balance the information regarding the positive and negative effects of the treatment, underlying the role of the positive ones despite its undesired effects, and by cognitively reinforcing the impact of the positive outcomes as they appear (74-76). Furthermore, it is possible to exploit conditioning mechanisms to support the pharmacological therapy. Once the person associates the characteristics of the analgesic agent, such as appearance and taste, to the reduction of pain, it could be possible to employ 
inert substitutes with the same characteristics to obtain similar results (6). Using similar methods, it would be possible, after an adequate initial conditioning, to progressively reduce the administration of medication by alternatively switching to a placebo with similar characteristics $(74,77)$. Finally, the patient can also be trained to create those conditions that maximize the placebo effect, for example by focusing on the characteristics of the analgesic agent or by increasing his own expectations through appropriate information (75).

It should be underscored that all these techniques need to take place within the context of a doctor-patient relationship. The relational aspect of the placebo effect resides in the person's feeling of being taken care for and in the process by which he himself becomes an active agent of the therapy (78). Having an empathic attitude, reassuring the patient, helping him to self-manage his symptoms, emphasizing the role of interpersonal resources and creating therapeutic rituals during therapy represent key aspects of the relationship.

In conclusion, the neurorehabilitation team needs to address a variety of disorders, each of which responds differently to the placebo effect. It is, therefore, necessary to personalize all these features depending on the disorder and on the patient's characteristics. Studies are beginning to clarify the genetic, biological, psychological, and contextual factors that may enable to identify subjects with high or low likelihood of experiencing a placebo response $(22,28)$. To exploit the placebo effect, the doctor should collect information regarding not only about the patient's disorder, but also about his personal characteristics and his context (74). The context of the doctor-patient relationship should be shaped so that the doctor does not focus only on the treatment of pain as a symptom of the neurological disorder, but is able to take care of the person as a whole.

\section{THE ITALIAN CONSENSUS CONFERENCE ON PAIN IN NEUROREHABILITATION}

The following Authors, who are listed in alphabetical order, contributed to the work of the Italian Consensus Conference on Pain in Neurorehabilitation: Michela Agostini, Neurorehabilitation Department, Foundation IRCCS San Camillo Hospital, Venice, Italy; Enrico Alfonsi, C. Mondino National Institute of Neurology Foundation, IRCCS, Pavia, Italy; Anna Maria Aloisi, Department of Medicine, Surgery and Neuroscience, University of Siena, Siena, Italy; Elena Alvisi, Department of Brain and Behavioural Sciences, University of Pavia, Pavia, Italy; Irene Aprile, Don Gnocchi Foundation, Milan, Italy; Michela Armando, Department of Neuroscience and Neurorehabilitation, Bambin Gesù Children's Hospital, IRCCS, Rome, Italy; Micol Avenali, C. Mondino National Institute of Neurology Foundation, IRCCS, Pavia, Italy, Department of Brain and Behavioural Sciences, University of Pavia, Pavia, Italy; Eva Azicnuda, IRCCS Santa Lucia Foundation, Rome, Italy; Francesco Barale, Department of Brain and Behavioural Sciences, University of Pavia, Pavia, Italy; Michelangelo Bartolo, Neurorehabilitation Unit, IRCCS INM Neuromed, Pozzilli, Italy; Roberto Bergamaschi, C. Mondino National Institute of Neurology Foundation, IRCCS, Pavia, Italy; Mariangela Berlangieri, Department of Brain and Behavioural
Sciences, University of Pavia, Pavia, Italy; Vanna Berlincioni, Department of Brain and Behavioural Sciences, University of Pavia, Pavia, Italy; Laura Berliocchi, Department of Health Sciences, University Magna Graecia of Catanzaro, Catanzaro, Italy; Eliana Berra, C. Mondino National Institute of Neurology Foundation, IRCCS, Pavia, Italy; Giulia Berto, Department of Neurological and Movement Sciences, University of Verona, Verona, Italy; Silvia Bonadiman, Department of Neurological and Movement Sciences, University of Verona, Verona, Italy; Sara Bonazza, Department of Surgery, University of Verona, Verona, Italy; Federica Bressi, Campus Biomedico University, Rome, Italy; Annalisa Brugnera, Department of Neurological and Movement Sciences, University of Verona, Verona, Italy; Stefano Brunelli, IRCCS Santa Lucia Foundation, Rome, Italy; Maria Gabriella Buzzi, IRCCS Santa Lucia Foundation, Rome, Italy; Carlo Cacciatori, Department of Neurological and Movement Sciences, University of Verona, Verona, Italy; Andrea Calvo, Rita Levi Montalcini Department of Neuroscience, University of Turin, Turin, Italy; Cristina Cantarella, Physical and Rehabilitation Medicine Unit, Tor Vergata University, Rome, Italy; Augusto Caraceni, Palliative Care, Pain Therapy and Rehabilitation, Fondazione IRCCS Istituto Nazionale dei Tumori di Milano, Milan, Italy; Roberto Carone, Neuro- Urology Department, City Hospital Health and Science of the City of Turin, Turin, Italy; Elena Carraro, Neuropediatric Rehabilitation Unit, E. Medea Scientific Institute, Conegliano, Italy; Roberto Casale, Department of Clinical Neurophysiology and Pain Rehabilitation Unit, Foundation Salvatore Maugeri IRCCS, Montescano, Italy; Paola Castellazzi, Department of Neurological and Movement Sciences, University of Verona, Verona, Italy; Gianluca Castelnuovo, Psychology Research Laboratory, Istituto Auxologico Italiano IRCCS, Ospedale San Giuseppe, Verbania, Italy, Department of Psychology, Catholic University of Milan, Italy; Adele Castino, ASL of the Province of Lodi, Lodi, Italy; Rosanna Cerbo, Hub Terapia del Dolore Regione Lazio, Policlinico Umberto I, Sapienza University, Rome Italy; Adriano Chiò, Rita Levi Montalcini Department of Neuroscience, University of Turin, Turin, Italy; Cristina Ciotti, Physical and Rehabilitation Medicine Unit, Tor Vergata University, Rome, Italy; Carlo Cisari, Department of Health Sciences, Università del Piemonte Orientale, Novara, Italy; Daniele Coraci, Department of Orthopaedic Science, Sapienza University, Rome, Italy; Elena Dalla Toffola, Department of Clinical, Surgical, Diagnostic and Pediatric Sciences, University of Pavia, Pavia, Italy, IRCCS Policlinico San Matteo Foundation, Pavia; Giovanni Defazio, Department of Basic Medical Sciences, Neuroscience and Sensory Organs, Aldo Moro University of Bari, Bari, Italy; Roberto De Icco, C. Mondino National Institute of Neurology Foundation, IRCCS, Pavia, Italy, Department of Brain and Behavioural Sciences, University of Pavia, Pavia, Italy; Ubaldo Del Carro, Section of Clinical Neurophysiology and Neurorehabilitation, San Raffaele Hospital, Milan, Italy; Andrea Dell'Isola, Department of Health Sciences, Università del Piemonte Orientale, Novara, Italy; Antonio De Tanti, Cardinal Ferrari Rehabilitation Center, Santo Stefano Rehabilitation Institute, Fontanellato, Italy; Mariagrazia D'Ippolito, IRCCS Santa Lucia Foundation, Rome, Italy; Elisa Fazzi, Childhood and Adolescence Neurology and Psychiatry Unit, City Hospital, 
Brescia, Italy, Department of Clinical and Experimental Sciences, University of Brescia, Brescia, Italy; Adriano Ferrari, Children Rehabilitation Unit, IRCCS Arcispedale S.Maria Nuova, Reggio Emilia, Italy; Sergio Ferrari, Department of Neurological and Movement Sciences, University of Verona, Verona, Italy; Francesco Ferraro, Section of Neuromotor Rehabilitation, Department of Neuroscience, Azienda Ospedaliera Carlo Poma, Mantova, Italy; Fabio Formaglio, Palliative Care, Pain Therapy and Rehabilitation, Fondazione IRCCS Istituto Nazionale dei Tumori di Milano, Milan, Italy; Rita Formisano, IRCCS Santa Lucia Foundation, Rome, Italy; Simone Franzoni, Poliambulanza Foundation Istituto Ospedaliero, Geriatric Research Group, Brescia, Italy; Francesca Gajofatto, Department of Neurological and Movement Sciences, University of Verona, Verona, Italy; Marialuisa Gandolfi, Department of Neurological and Movement Sciences, University of Verona, Verona, Italy; Barbara Gardella, IRCCS Policlinico San Matteo Foundation, Pavia; Pierangelo Geppetti, Department of Health Sciences, Section of Clinical Pharmacology and Oncology, University of Florence, Florence, Italy; Alessandro Giammò, Neuro-Urology Department, City Hospital Health and Science of the City of Turin, Turin, Italy; Raffaele Gimigliano, Department of Physical and Mental Health, Second University of Naples, Naples, Italy; Emanuele Maria Giusti, Department of Psychology, Catholic University of Milan, Italy; Elena Greco, Department of Neurological and Movement Sciences, University of Verona, Verona, Italy; Valentina Ieraci, Department of Oncology and Neuroscience, University of Turin, City Hospital Health and Science of the City of Turin, Turin, Turin, Italy; Marco Invernizzi, Department of Health Sciences, Università del Piemonte Orientale, Novara, Italy; Marco Jacopetti, University of Parma, Parma, Italy; Marco Lacerenza, Casa di Cura San Pio X S.r.l., HUMANITAS, Milan, Italy; Silvia La Cesa, Department of Neurology and Psychiatry, University Sapienza, Rome, Italy; Davide Lobba, Department of Neurological and Movement Sciences, University of Verona, Verona, Italy; Gian Mauro Manzoni, Psychology Research Laboratory, Istituto Auxologico Italiano IRCCS, Ospedale San Giuseppe, Verbania, Italy, Department of Psychology, Catholic University of Milan, Italy; Francesca Magrinelli, Department of Neurological and Movement Sciences, University of Verona, Verona, Italy; Silvia Mandrini, Department of Clinical, Surgical, Diagnostic and Pediatric Sciences, University of Pavia, Pavia, Italy; Umberto Manera, Rita Levi Montalcini Department of Neuroscience, University of Turin, Turin, Italy; Paolo Marchettini, Pain Medicine Center, Hospital San Raffaele, Milan, Italy; Enrico Marchioni, C. Mondino National Institute of Neurology Foundation, IRCCS, Pavia, Italy; Sara Mariotto, Department of Neurological and Movement Sciences, University of Verona, Verona, Italy; Andrea Martinuzzi, Neuropediatric Rehabilitation Unit, E. Medea Scientific Institute, Conegliano, Italy; Marella Masciullo, IRCCS Santa Lucia Foundation, Rome, Italy; Susanna Mezzarobba, Department of Medicine, Surgery and Health Sciences, University of Trieste, Trieste, Italy; Danilo Miotti, Palliative Care and Pain Therapy Unit, Fondazione Salvatore Maugeri IRCCS, Scientific Institute of Pavia, Pavia, Italy; Angela Modenese, Department of Neurological and Movement Sciences, University of Verona, Verona, Italy; Marco Molinari, IRCCS
Santa Lucia Foundation, Rome, Italy; Salvatore Monaco, Department of Neurological and Movement Sciences, University of Verona, Verona, Italy; Giovanni Morone, IRCCS Santa Lucia Foundation, Rome, Italy; Rossella Nappi, Department of Clinical, Surgical, Diagnostic and Pediatric Sciences, University of Pavia, Pavia, Italy, IRCCS Policlinico San Matteo Foundation, Pavia; Stefano Negrini, Don Gnocchi Foundation, Milan, Italy, Department of Clinical and Experimental Sciences, University of Brescia, Brescia, Italy; Andrea Pace, Neuro-Oncology Unit, Regina Elena National Cancer Institute of Rome, Rome, Italy; Luca Padua, Don Gnocchi Foundation, Milan, Italy, Institute of Neurology, Catholic University, Rome, Italy; Emanuela Pagliano, Developmental Neurology Unit, C. Besta Neurological Institute Foundation, Milan, Italy; Valerio Palmerini, Hub Terapia del Dolore Regione Lazio, Policlinico Umberto I, Sapienza University, Rome Italy; Stefano Paolucci, IRCCS Santa Lucia Foundation, Rome, Italy; Costanza Pazzaglia, Don Gnocchi Foundation, Milan, Italy; Cristiano Pecchioli, Don Gnocchi Foundation, Milan, Italy; Alessandro Picelli, Department of Neurological and Movement Sciences, University of Verona, Verona, Italy; Carlo Adolfo Porro, Department of Biomedical, Metabolic and Neural Sciences, University of Modena and Reggio Emilia, Modena, Italy; Daniele Porru, IRCCS Policlinico San Matteo Foundation, Pavia; Marcello Romano, Neurology Unit, Azienda Ospedaliera Ospedali Riuniti Villa Sofia Cervello, Palermo, Italy; Laura Roncari, Department of Neurological and Movement Sciences, University of Verona, Verona, Italy; Riccardo Rosa, Hub Terapia del Dolore Regione Lazio, Policlinico Umberto I, Sapienza University, Rome Italy; Marsilio Saccavini, ASL 2 Bassa FriulanaIsontina, Italy; Paola Sacerdote, Department of Pharmacological and Biomolecular Sciences, University of Milano, Milano, Italy; Giorgio Sandrini, C. Mondino National Institute of Neurology Foundation, IRCCS, Pavia, Italy, Department of Brain and Behavioural Sciences, University of Pavia, Pavia, Italy; Donatella Saviola, Cardinal Ferrari Rehabilitation Center, Santo Stefano Rehabilitation Institute, Fontanellato, Italy; Angelo Schenone, Department of Neuroscience, Rehabilitation, Ophthalmology, Genetics, Maternal and Child Health (DiNOGMI), University of Genoa, Genoa, Italy; Vittorio Schweiger, Department of Surgery, University of Verona, Verona, Italy; Giorgio Scivoletto, IRCCS Santa Lucia Foundation, Rome, Italy; Nicola Smania, Department of Neurological and Movement Sciences, University of Verona, Verona, Italy; Claudio Solaro, Neurology Unit, ASL3, Genoa, Italy; Vincenza Spallone, Department of Systems Medicine, University Tor Vergata, Rome, Italy; Isabella Springhetti, Functional Recovery and Rehabilitation Unit, IRCCS Fondazione S. Maugeri, Pavia, Italy; Stefano Tamburin, Department of Neurological and Movement Sciences, University of Verona, Verona, Italy; Cristina Tassorelli, C. Mondino National Institute of Neurology Foundation, IRCCS, Pavia, Italy, Department of Brain and Behavioural Sciences, University of Pavia, Pavia, Italy; Michele Tinazzi, Department of Neurological and Movement Sciences, University of Verona, Verona, Italy; Rossella Togni, Department of Clinical, Surgical, Diagnostic and Pediatric Sciences, University of Pavia, Pavia, Italy; Monica Torre, IRCCS Santa Lucia Foundation, Rome, Italy; Riccardo Torta, Department of Oncology and Neuroscience, University of Turin, City Hospital 
Health and Science of the City of Turin, Turin, Turin, Italy; Marco Traballesi, IRCCS Santa Lucia Foundation, Rome, Italy; Marco Tramontano, IRCCS Santa Lucia Foundation, Rome, Italy; Andrea Truini, Department of Neurology and Psychiatry, University Sapienza, Rome, Italy; Valeria Tugnoli, Neurological Unit, University Hospital of Ferrara, Ferrara, Italy; Andrea Turolla, Neurorehabilitation Department, Foundation IRCCS San Camillo Hospital, Venice, Italy; Gabriella Vallies, Department of Neurological and Movement Sciences, University of Verona, Verona, Italy; Elisabetta Verzini, Department of Neurological and Movement Sciences, University of Verona, Verona, Italy; Mario Vottero, Neuro-Urology Department, City Hospital Health and Science of the City of Turin, Turin, Italy; Paolo Zerbinati,

\section{REFERENCES}

1. Benedetti F, Frisaldi E, Carlino E, Giudetti L, Pampallona A, Zibetti M, et al. Teaching neurons to respond to placebos. J Physiol (2016) 594:5647-60. doi:10.1113/JP271322

2. Dodd S, Dean OM, Vian J, Berk M. A review of the theoretical and biological understanding of the nocebo and placebo phenomena. Clin Ther (2017) 39:469-76. doi:10.1016/j.clinthera.2017.01.010

3. Benrud-Larson LM, Wegener ST. Chronic pain in neurorehabilitation populations: prevalence, severity and impact. NeuroRehabilitation (2000) 14:127-37.

4. Magrinelli F, Zanette G, Tamburin S. Neuropathic pain: diagnosis and treatment. Pract Neurol (2013) 13:292-307. doi:10.1136/practneurol-2013-000536

5. Tamburin S, Paolucci S, Magrinelli F, Musicco M, Sandrini G. The Italian Consensus Conference on Pain in Neurorehabilitation: rationale and methodology. J Pain Res (2016) 9:311-8. doi:10.2147/JPR.S84646

6. Klinger R, Flor H. Clinical and ethical implications of placebo effects: enhancing patients' benefits from pain treatment. Handb Exp Pharmacol (2014) 225:217-35. doi:10.1007/978-3-662-44519-8_13

7. Miller FG, Kaptchuk TJ. The power of context: reconceptualizing the placebo effect. J R Soc Med (2008) 101:222-5. doi:10.1258/jrsm.2008.070466

8. Price DD, Finniss DG, Benedetti F. A comprehensive review of the placebo effect: recent advances and current thought. Annu Rev Psychol (2008) 59:565-90. doi:10.1146/annurev.psych.59.113006.095941

9. Crane GS. Harnessing the placebo effect: a new model for mind-body healing mechanisms. Int J Trans Stud (2016) 35:39-51. doi:10.24972/ijts.2016.35.1.39

10. Benedetti F. Placebo and the new physiology of the doctor-patient relationship. Physiol Rev (2013) 93:1207-46. doi:10.1152/physrev.00043.2012

11. Benedetti F. Placebo-induced improvements: how therapeutic rituals affect the patient's brain. J Acupunct Meridian Stud (2012) 5:97-103. doi:10.1016/j. jams.2012.03.001

12. Colagiuri B, Schenk LA, Kessler MD, Dorsey SG, Colloca L. The placebo effect: from concepts to genes. Neuroscience (2015) 307:171-90. doi:10.1016/j. neuroscience.2015.08.017

13. Levine JD, Gordon NC, Fields HL. The mechanism of placebo analgesia. Lancet (1978) 2:654-7. doi:10.1016/S0140-6736(78)92762-9

14. Benedetti F, Amanzio M, Casadio C, Oliaro A, Maggi G. Blockade of nocebo hyperalgesia by the cholecystokinin antagonist proglumide. Pain (1997) 71:135-40. doi:10.1016/S0304-3959(97)03346-0

15. Amanzio M, Benedetti F. Neuropharmacological dissection of placebo analgesia: expectation-activated opioid systems versus conditioning-activated specific subsystems. J Neurosci (1999) 19:484-94. doi:10.1523/JNEUROSCI.19-01-00484. 1999

16. Scott DJ, Stohler CS, Egnatuk CM, Wang H, Koeppe RA, Zubieta JK. Individual differences in reward responding explain placebo-induced expectations and effects. Neuron (2007) 55:325-36. doi:10.1016/j.neuron.2007.06.028

17. Scott DJ, Stohler CS, Egnatuk CM, Wang H, Koeppe RA, Zubieta JK. Placebo and nocebo effects are defined by opposite opioid and dopaminergic responses. Arch Gen Psychiatry (2008) 65:220-31. doi:10.1001/archgenpsychiatry.2007.34

18. Eippert F, Bingel U, Schoell ED, Yacubian J, Klinger R, Lorenz J, et al. Activation of the opioidergic descending pain control system underlies placebo analgesia. Neuron (2009) 63:533-43. doi:10.1016/j.neuron.2009.07.014
Neuro- orthopaedic Program, Hand Surgery Department, Santa Maria Hospital MultiMedica, Castellanza, Italy.

\section{AUTHOR'S NOTE}

This paper has been written and shared in the Consensus Conference modality.

\section{AUTHOR CONTRIBUTIONS}

All authors listed have made a substantial, direct and intellectual contribution to the work, and approved it for publication.

19. Zubieta J-K, Stohler CS. Neurobiological mechanisms of placebo responses. Ann N Y Acad Sci (2009) 1156:198-210. doi:10.1111/j.1749-6632.2009. 04424.x

20. Benedetti F, Amanzio M, Rosato R, Blanchard C. Nonopioid placebo analgesia is mediated by CB1 cannabinoid receptors. Nat Med (2011) 17:1228-30. doi: $10.1038 / \mathrm{nm} .2435$

21. Carlino E, Piedimonte A, Benedetti F. Nature of the placebo and nocebo effect in relation to functional neurologic disorders. Handb Clin Neurol (2017) 139:597-606. doi:10.1016/B978-0-12-801772-2.00048-5

22. Wang RS, Hall KT, Giulianini F, Passow D, Kaptchuk TJ, Loscalzo J. Network analysis of the genomic basis of the placebo effect. JCI Insight (2017) 2:93911. doi:10.1172/jci.insight.93911

23. Hall KT, Loscalzo J, Kaptchuk T. Pharmacogenomics and the placebo response. ACS Chem Neurosci (2018) 9(4):633-5. doi:10.1021/acschemneuro. $8 \mathrm{~b} 00078$

24. Wager TD, Atlas LY, Leotti LA, Rilling JK. Predicting individual differ ences in placebo analgesia: contributions of brain activity during anticipation and pain experience. JNeurosci (2011) 31:439-52. doi:10.1523/ JNEUROSCI.3420-10.2011

25. Geers AL, Helfer SG, Kosbab K, Weiland PE, Landry SJ. Reconsidering the role of personality in placebo effects: dispositional optimism, situational expectations, and the placebo response. J Psychosom Res (2005) 58:121-7. doi:10.1016/j.jpsychores.2004.08.011

26. Morton DL, Watson A, El-Deredy W, Jones AK. Reproducibility of placebo analgesia: effect of dispositional optimism. Pain (2009) 146:194-8. doi:10.1016/j. pain.2009.07.026

27. Geers AL, Wellman JA, Fowler SL, Helfer SG, France CR. Dispositional optimism predicts placebo analgesia. J Pain (2010) 11:1165-71. doi:10.1016/j. jpain.2010.02.014

28. Pecina M, Azhar H, Love TM, Lu T, Fredrickson BL, Stohler CS, et al. Personality trait predictors of placebo analgesia and neurobiological correlates. Neuropsychopharmacology (2013) 38:639-46. doi:10.1038/npp.2012.227

29. Darragh M, Booth RJ, Consedine NS. Who responds to placebos? Considering the "placebo personality" via a transactional model. Psychol Health Med(2015) 20:287-95. doi:10.1080/13548506.2014.936885

30. De Pascalis V, Chiaradia C, Carotenuto E. The contribution of suggestibility and expectation to placebo analgesia phenomenon in an experimental setting. Pain (2002) 96:393-402. doi:10.1016/S0304-3959(01)00485-7

31. Raz A. Genetics and neuroimaging of attention and hypnotizability may elucidate placebo. Int JClin Exp Hypn (2008) 56:99-116. doi:10.1080/ 00207140701506482

32. Van Der Meulen M, Kamping S, Anton F. The role of cognitive reappraisal in placebo analgesia: an fMRI study. Soc Cogn Affect Neurosci (2017) 12(7): 1128-37. doi:10.1093/scan/nsx033

33. Watkinson A, Chapman SC, Horne R. Beliefs about pharmaceutical medicines and natural remedies explain individual variation in placebo analgesia. J Pain (2017) 18(8):908-22. doi:10.1016/j.jpain.2017.02.435

34. Colloca L, Benedetti F. How prior experience shapes placebo analgesia. Pain (2006) 124:126-33. doi:10.1016/j.pain.2006.04.005

35. Schweinhardt P, Seminowicz DA, Jaeger E, Duncan GH, Bushnell MC. The anatomy of the mesolimbic reward system: a link between personality and 
the placebo analgesic response. JNeurosci (2009) 29:4882-7. doi:10.1523/ JNEUROSCI.5634-08.2009

36. Aromataris E, Fernandez R, Godfrey CM, Holly C, Khalil H, Tungpunkom P. Summarizing systematic reviews: methodological development, conduct and reporting of an umbrella review approach. Int J Evid Based Healthc (2015) 13:132-40. doi:10.1097/XEB.0000000000000055

37. Mbizvo GK, Nolan SJ, Nurmikko TJ, Goebel A. Placebo responses in long-standing complex regional pain syndrome: a systematic review and meta-analysis. J Pain (2015) 16:99-115. doi:10.1016/j.jpain.2014.11.008

38. Hauser W, Sarzi-Puttini P, Tolle TR, Wolfe F. Placebo and nocebo responses in randomised controlled trials of drugs applying for approval for fibromyalgia syndrome treatment: systematic review and meta-analysis. Clin Exp Rheumatol (2012) 30:78-87.

39. Loder E, Goldstein R, Biondi D. Placebo effects in oral triptan trials: the scientific and ethical rationale for continued use of placebo controls. Cephalalgia (2005) 25:124-31. doi:10.1111/j.1468-2982.2004.00817.x

40. Macedo A, Banos JE, Farre M. Placebo response in the prophylaxis of migraine: a meta-analysis. Eur J Pain (2008) 12:68-75. doi:10.1016/j.ejpain.2007.03.002

41. Meissner K, Fassler M, Rucker G, Kleijnen J, Hrobjartsson A, Schneider A, et al. Differential effectiveness of placebo treatments: a systematic review of migraine prophylaxis. JAMA Intern Med (2013) 173:1941-51. doi:10.1001/ jamainternmed.2013.10391

42. Cragg JJ, Warner FM, Finnerup NB, Jensen MP, Mercier C, Richards JS, et al. Meta-analysis of placebo responses in central neuropathic pain: impact of subject, study, and pain characteristics. Pain (2016) 157:530-40. doi:10.1097/j. pain. 0000000000000431

43. Arakawa A, Kaneko M, Narukawa M. An investigation of factors contributing to higher levels of placebo response in clinical trials in neuropathic pain: a systematic review and meta-analysis. Clin Drug Investig (2015) 35:67-81. doi:10.1007/s40261-014-0259-1

44. Cepeda MS, Berlin JA, Gao CY, Wiegand F, Wada DR. Placebo response changes depending on the neuropathic pain syndrome: results of a systematic review and meta-analysis.PainMed(2012)13:575-95.doi:10.1111/j.1526-4637.2012.01340.x

45. Quessy SN, Rowbotham MC. Placebo response in neuropathic pain trials. Pain (2008) 138:479-83. doi:10.1016/j.pain.2008.06.024

46. Tuttle AH, Tohyama S, Ramsay T, Kimmelman J, Schweinhardt P, Bennett GJ, et al. Increasing placebo responses over time in U.S. clinical trials of neuropathic pain. Pain (2015) 156:2616-26. doi:10.1097/j.pain.0000000000000333

47. Madsen MV, Gotzsche PC, Hrobjartsson A. Acupuncture treatment for pain: systematic review of randomised clinical trials with acupuncture, placebo acupuncture, and no acupuncture groups. BMJ (2009) 338:a3115. doi:10.1136/ bmj.a3115

48. Naleschinski D, Baron R. Complex regional pain syndrome type I: neuropathic or not? Curr Pain Headache Rep (2010) 14:196-202. doi:10.1007/ s11916-010-0115-9

49. Amanzio M, Corazzini LL, Vase L, Benedetti F. A systematic review of adverse events in placebo groups of anti-migraine clinical trials. Pain (2009) 146:261-9. doi:10.1016/j.pain.2009.07.010

50. Zhang W, Robertson J, Jones AC, Dieppe PA, Doherty M. The placebo effect and its determinants in osteoarthritis: meta-analysis of randomised controlled trials. Ann Rheum Dis (2008) 67:1716-23. doi:10.1136/ard.2008.092015

51. Bannuru RR, Mcalindon TE, Sullivan MC, Wong JB, Kent DM, Schmid CH. Effectiveness and implications of alternative placebo treatments: a systematic review and network meta-analysis of osteoarthritis trials. Ann Intern Med (2015) 163:365-72. doi:10.7326/M15-0623

52. Kuten-Shorrer M, Kelley JM, Sonis ST, Treister NS. Placebo effect in burning mouth syndrome: a systematic review. Oral Dis (2014) 20:e1-6. doi:10.1111/ odi. 12192

53. Capurso G, Cocomello L, Benedetto U, Camma C, Delle Fave G. Meta-analysis: the placebo rate of abdominal pain remission in clinical trials of chronic pancreatitis. Pancreas (2012) 41:1125-31. doi:10.1097/ MPA.0b013e318249ce93

54. Hrobjartsson A, Gotzsche PC. Is the placebo powerless? Update of a systematic review with 52 new randomized trials comparing placebo with no treatment. J Intern Med (2004) 256:91-100. doi:10.1111/j.1365-2796.2004. 01355. $\mathrm{x}$

55. Wager TD, Fields HL. Placebo analgesia. 6th ed. In: Mcmahon SB, Koltzenburg M, Tracey I, Turk D, editors. Wall and Melzack's Textbook of Pain. Philadelhia, PA: Elsevier Saunders (2013). p. 362-73.
56. Vase L, Skyt I, Hall KT. Placebo, nocebo, and neuropathic pain. Pain (2016) 157(Suppl 1):S98-105. doi:10.1097/j.pain.0000000000000445

57. Vase L, Petersen GL, Riley JL III, Price DD. Factors contributing to large analgesic effects in placebo mechanism studies conducted between 2002 and 2007. Pain (2009) 145:36-44. doi:10.1016/j.pain.2009.04.008

58. Bartolo M, Chio A, Ferrari S, Tassorelli C, Tamburin S, Avenali M, et al. Assessing and treating pain in movement disorders, amyotrophic lateral sclerosis, severe acquired brain injury, disorders of consciousness, dementia, oncology and neuroinfectivology. Evidence and recommendations from the Italian Consensus Conference on Pain in Neurorehabilitation. Eur J Phys Rehabil Med (2016) 52:841-54.

59. Castelnuovo G, Giusti EM, Manzoni GM, Saviola D, Gatti A, Gabrielli S, et al. Psychological considerations in the assessment and treatment of pain in neurorehabilitation and psychological factors predictive of therapeutic response: evidence and recommendations from the Italian consensus conference on pain in neurorehabilitation. Front Psychol (2016) 7:468. doi:10.3389/ fpsyg. 2016.00468

60. Castelnuovo G, Giusti EM, Manzoni GM, Saviola D, Gatti A, Gabrielli S, et al. Psychological treatments and psychotherapies in the neurorehabilitation of pain: evidences and recommendations from the Italian consensus conference on pain in neurorehabilitation. Front Psychol (2016) 7:115. doi:10.3389/ fpsyg.2016.00115

61. Ferraro F, Jacopetti M, Spallone V, Padua L, Traballesi M, Brunelli S, et al. Diagnosis and treatment of pain in plexopathy, radiculopathy, peripheral neuropathy and phantom limb pain. Evidence and recommendations from the Italian Consensus Conference on Pain on Neurorehabilitation. Eur J Phys Rehabil Med (2016) 52:855-66.

62. Paolucci S, Martinuzzi A, Scivoletto G, Smania N, Solaro C, Aprile I, et al. Assessing and treating pain associated with stroke, multiple sclerosis, cerebral palsy, spinal cord injury and spasticity. Evidence and recommendations from the Italian Consensus Conference on Pain in Neurorehabilitation. Eur J Phys Rehabil Med (2016) 52:827-40.

63. Picelli A, Buzzi MG, Cisari C, Gandolfi M, Porru D, Bonadiman S, et al. Headache, low back pain, other nociceptive and mixed pain conditions in neurorehabilitation. Evidence and recommendations from the Italian Consensus Conference on Pain in Neurorehabilitation. Eur J Phys Rehabil Med (2016) 52:867-80.

64. Tamburin S, Lacerenza MR, Castelnuovo G, Agostini M, Paolucci S, Bartolo M, et al. Pharmacological and non-pharmacological strategies in the integrated treatment of pain in neurorehabilitation. Evidence and recommendations from the Italian Consensus Conference on Pain in Neurorehabilitation. Eur J Phys Rehabil Med (2016) 52:741-52.

65. Kaptchuk TJ, Friedlander E, Kelley JM, Sanchez MN, Kokkotou E, Singer JP, et al. Placebos without deception: a randomized controlled trial in irritable bowel syndrome. PLoS One (2010) 5:e15591. doi:10.1371/journal. pone.0015591

66. Kam-Hansen S, Jakubowski M, Kelley JM, Kirsch I, Hoaglin DC, Kaptchuk TJ, et al. Altered placebo and drug labeling changes the outcome of episodic migraine attacks. Sci Transl Med (2014) 6:218ra215. doi:10.1126/scitranslmed. 3006175

67. Carvalho C, Caetano JM, Cunha L, Rebouta P, Kaptchuk TJ, Kirsch I. Openlabel placebo treatment in chronic low back pain: a randomized controlled trial. Pain (2016) 157:2766-72. doi:10.1097/j.pain.0000000000000700

68. Charlesworth JEG, Petkovic G, Kelley JM, Hunter M, Onakpoya I, Roberts N, et al. Effects of placebos without deception compared with no treatment: a systematic review and meta-analysis. J Evid Based Med (2017) 10:97-107. doi:10.1111/jebm.12251

69. Locher C, Frey Nascimento A, Kirsch I, Kossowsky J, Meyer A, Gaab J. Is the rationale more important than deception? A randomized controlled trial of open-label placebo analgesia. Pain (2017) 158(12):2320-8. doi:10.1097/j. pain. 0000000000001012

70. Mundt JM, Roditi D, Robinson ME. A comparison of deceptive and nondeceptive placebo analgesia: efficacy and ethical consequences. Ann Behav Med (2017) 51:307-15. doi:10.1007/s12160-016-9854-0

71. Martin AL, Katz J. Inclusion of authorized deception in the informed consent process does not affect the magnitude of the placebo effect for experimentally induced pain. Pain (2010) 149:208-15. doi:10.1016/j.pain.2009.12.004

72. Brody $\mathrm{H}$. The lie that heals: the ethics of giving placebos. Ann Intern Med (1982) 97:112-8. doi:10.7326/0003-4819-97-1-112 
73. Finniss DG, Kaptchuk TJ, Miller F, Benedetti F. Placebo effects: biological, clinical and ethical advances. Lancet (2010) 375:686-95. doi:10.1016/ S0140-6736(09)61706-2

74. Enck P, Bingel U, Schedlowski M, Rief W. The placebo response in medicine: minimize, maximize or personalize? Nat Rev Drug Discov (2013) 12:191-204. doi: $10.1038 / \mathrm{nrd} 3923$

75. Klinger R, Colloca L, Bingel U, Flor H. Placebo analgesia: clinical applications. Pain (2014) 155:1055-8. doi:10.1016/j.pain.2013.12.007

76. Bystad M, Bystad C, Wynn R. How can placebo effects best be applied in clinical practice? A narrative review. Psychol Res Behav Manage (2015) 8:41-5. doi:10.2147/PRBM.S75670

77. Doering BK, Rief W. Utilizing placebo mechanisms for dose reduction in pharmacotherapy. Trends Pharmacol Sci (2012) 33:165-72. doi:10.1016/j.tips.2011.12.001

78. Barrett B, Muller D, Rakel D, Rabago D, Marchand L, Scheder JC. Placebo, meaning, and health. Perspect Biol Med (2006) 49:178-98. doi:10.1353/ pbm.2006.0019
Conflict of Interest Statement: The authors declare that the research was conducted in the absence of any commercial or financial relationships that could be construed as a potential conflict of interest.

Copyright (c) 2018 Castelnuovo, Giusti, Manzoni, Saviola, Gabrielli, Lacerenza, Pietrabissa, Cattivelli, Spatola, Rossi, Varallo, Novelli, Villa, Luzzati, Cottini, Lai, Volpato, Cavalera, Pagnini, Tesio, Castelli, Tavola, Torta, Arreghini, Zanini, Brunani, Seitanidis, Ventura, Capodaglio, D’Aniello, Scarpina, Brioschi, Bigoni, Priano, Mauro, Riva, Di Lernia, Repetto, Regalia, Molinari, Notaro, Paolucci, Sandrini, Simpson, Wiederhold, Gaudio, Jackson, Tamburin, Benedetti. This is an open-access article distributed under the terms of the Creative Commons Attribution License (CC BY). The use, distribution or reproduction in other forums is permitted, provided the original author(s) and the copyright owner are credited and that the original publication in this journal is cited, in accordance with accepted academic practice. No use, distribution or reproduction is permitted which does not comply with these terms. 